Sir,

\section{Homonymous hemianopia and driving}

With interest we read the letter by Mukherji and Burgess, in the May issue 2002 of Eye, pp 321-322.

From experience, we know that attributing visual field loss to a certain cause may be a cumbersome procedure ${ }^{1}$ especially as in their Case 2 where no abnormality was found on neurophthalmologic examination. We might have liked to see a note or fundus picture, ruling out, for example, tilted discs. Did they test in Case 1 the full field or only the central one?

The main reason why we are writing to you is that we were struck by the apparent automatism by which a 35year-old woman with right homonymous hemianopia was taken off the road by the Driver and Vehicle Licensing Agency. According to the case report, she was not aware of her field defect and had no driving problems. We assume that she passed without problems her driving licence exam with the same defect.

In order to instigate a change in the European and national directives, research by the CBR (the Netherlands Driving Licence Authority) was started amongst 63 persons with serious visual field defects (in particular, homonymous hemianopia). The procedure was to test the visual field carefully, and in this way often $5-10^{\circ}$ sparing of the macular field on the hemianopic side was found. Furthermore applicants were checked if there were any concomitant disorders, in neurophthalmic cases by a neurologist too. If not, these people were referred to the department of the CBR specialized in evaluating disabled drivers by trained examiners according to a specific protocol. There they had to undergo a practical driving test in a normal car on the public road of approximately $1 \mathrm{hr}$ in different traffic conditions. Medical approval was given to those people who thus had proven that they could function as an adequate driver.

The results were that the second European directive (1991), ${ }^{2}$ implemented by all member states in 1996, offers more possibilities for drivers with field of vision disorders, a success for The Netherlands and Belgium who made out a case for this. The council directive of 29 July 1991 stipulates in annex 111: 'Driving licences (group 1 , passenger cars) shall not be issued or renewed if, during the medical examination, it is shown that the horizontal field of vision is less that $120^{\circ}$, apart from exceptional cases duly justified by a favourable medical opinion and positive practical test'.

In the Netherlands, there are now over 300 drivers with right- or left-sided hemianopia. Remarkably, in daily practice, it does not seem to matter on which side this is - this given the fact that in the Netherlands drivers have to give priority to traffic from the right on an equal road crossing and that with right-hand driving one has to scan oncoming traffic on the left side when overtaking a car. With adequate compensation mechanisms, among others more scanning eye and head movements, these people drive as well as most other drivers.

As there is a lack of good literature showing the association between visual field loss and crash involvement, ${ }^{3}$ we would recommend, especially for such a young subject as Case 1, a finer tuning procedure.

\section{References}

1 Ramrattan RS, Wolf RC, Panda-Jonas S, Jonas JB, Bakker D, Pols HA et al. Prevalence and causes of visual field loss in the elderly and associations with impairment in daily functioning: the Rotterdam Study. Arch Ophthalmol 2001; 119: 1788-1794.

2 Council of European Communities. Minimum standards of physical and mental fitness for driving a power-driven vehicle. Council directive of 29 July 1991 on driving licences (91/439/EEC) Annex 111, 1991.

3 Owsley C, McGwin G. Vision impairment and driving. Surv Ophthalmol 1999; 43: 535-550.

PTVM de Jong ${ }^{1,2,3}$ and $\mathrm{HH}$ Warmink $^{4}$

${ }^{1}$ The Netherlands Ophthalmic Research Institute KNAW, Amsterdam

${ }^{2}$ Department of Ophthalmology,

Academic Medical Center, Amsterdam

${ }^{3}$ Department of Epidemiology and Biostatistics

Rotterdam

${ }^{4} \mathrm{KLM}$ Aeromedical Institute, Schiphol Airport

Amsterdam, The Netherlands

Correspondence: Dr PTVM de Jong

Department of Ophthalmogenetics

Meibergdreef 47

1105 BA Amsterdam

The Netherlands

Tel: +31205664588

Fax: +31205669050

E-mail: p.dejong@ioi.knaw.nl

Eye (2003) 17, 545. doi:10.1038/sj.eye.6700395

Sir,

\section{Reply: Homonymous hemianopia and driving}

We read with interest the comments of Dr de Jong and his colleague on 'Visual field defects in adults secondary to preterm delivery'. 